\title{
Hepatotoxicidade associada à microcistina
}

\section{Hepatotoxicity associated with microcystin}

\author{
Ana Paula Millet Evangelista dos Santos ${ }^{1}$; \\ Ana Paula Frederico Rodrigues Loureiro Bracarense ${ }^{2 *}$
}

\section{Resumo}

Efluentes industriais e urbanos e a intensa exploração agrícola e de pescado têm levado à eutrofização de muitos mananciais de água, destinados ao consumo e às atividades recreacionais. A eutrofização das águas, freqüentemente, tem como conseqüência o desenvolvimento expressivo de cianobactérias. Estas florações induzem a sérios problemas, visto que a ocorrência de Microcystis aeruginosa, uma das cianobactérias mais difundidas, pode produzir microcistinas (MCs). O efeito citotóxico da $\mathrm{MC}$ tem sido descrito no fígado, pulmões, estômago e intestino. Mortes de seres humanos, de animais silvestres e domésticos têm sido associadas à exposição a MC. Esta pode ocorrer diretamente por ingestão, inalação, contato, inoculação intravenosa (hemodiálise) ou indiretamente, pelo consumo de animais, dentre os quais os peixes e moluscos, que podem ingerir as cianobactérias e suas toxinas. A mais tóxica e também mais comum das MCs é a microcistina-LR (MC-LR), cujo órgão alvo é o fígado. A MC chega ao fígado especificamente por transporte dos ácidos biliares e, uma vez no citoplasma, inibe as proteínas fosfatases 1 e 2A, induzindo ao aumento da fosforilação protéica. Esta reação tem duas conseqüências: destruição do citoesqueleto, causando efeitos citotóxicos e descontrole da divisão celular, levando à promoção tumoral. A exposição aguda à MC induz severa hemorragia intra-hepática, necrose e apoptose, enquanto a exposição crônica pode causar neoplasia hepática ou intestinal. Também tem sido relatado que a hepatotoxicidade da MC está intimamente associada à formação intracelular de espécies reativas de oxigênio. A MC pode ser naturalmente degradada por bactérias ou pela radiação solar. Contudo, se não houver eficiente degradação, a MC poderá persistir na cadeia alimentar aquática. A contaminação de águas pela $\mathrm{MC}$ representa, portanto, perigo à saúde humana e de animais. Assim, esforços para evitar a eutrofização de fontes de águas são essenciais para minimizar riscos à saúde pública.

Palavras-chave: Microcystis aeruginosa, microcistina, cianotoxinas, hepatotoxina

\begin{abstract}
Urban and industrial discharges, intense agricultural exploitation and fisheries have been causing the eutrophication in both drinking and recreational waters. A frequent consequence of eutrophication in waters is the massive development of cyanobacteria. The occurrence of these blooms induces a severe problem, as Microcystis aeruginosa, the most widespread distributed cyanobacteria, can produce microcystins (MC). Toxic effects of MC have been described in liver, lungs, stomach, and intestine. Deaths in wildlife, livestock and human beings were also associated with MC exposition. MC exposition can occurs directly by ingestion, inhalation, contact, intravenous inoculation of contaminated water (hemodialysis) or indirectly, by the consumption of animals, as fish and mollusks, the majors ingestors of cyanobacteria and its toxins. The most
\end{abstract}

\footnotetext{
1 Prof. Ass., Depto. Medicina Veterinária e Produção Animal - Fundação Faculdades Luiz Meneghel (FFALM), Bandeirantes-PR. Aluna do Programa de Pós-Graduação em Ciência Animal - Universidade Estadual de Londrina - PR (UEL-PR). E-mail: ap_millet@hotmail.com.

2 Prof. Assoc., Depto. Medicina Veterinária Preventiva - UEL-PR. Bolsa Produtividade em Pesquisa, CNPq. E-mail: anapaula@uel.br

* Autor para correspondência
} 
toxic MC, an also the most common is microcystin-LR (MC-LR), that has the liver as the main target organ. Microcystin is taken up specifically into the liver by bile acid transporters and, after entering the cytoplasm, inhibit protein phosphatases 1 and 2A, which leads to the increase in protein phosphorylation. This effect has two main consequences: the destruction of cytoskeleton directly causing cytotoxic effects, and deregulation of cell division, leading to tumor-promoting activity. Acute exposition to $\mathrm{MC}$ induces severe intrahepatic hemorrhage, necrosis and apoptosis, while chronic exposure can cause hepatic or intestinal neoplasia. It has been documented that $\mathrm{MC}$ hepatotoxicity is closely associated with intracellular reactive oxygen species formation. Natural degradation of microcystins depends on the solar radiation and bacteria. If degradation is insufficient, $\mathrm{MC}$ will persist in the freshwater food chain. Microcystin contamination of waters is therefore a hazard to human and animal health, so efforts to avoid eutrophication of waters sources are essential, in order to minimize the risks to public health.

Key words: Microcystis aeruginosa, microcystin, cyanobacterial toxins, hepatotoxin

\section{Introdução}

Prosseguir com o desenvolvimento industrial e tecnológico e ainda, preservar os diversos ecossistemas e recuperar o equilíbrio ecológico é talvez um dos maiores desafios do homem neste século XXI. A contaminação ambiental tem ocorrido de forma intencional ou acidental, principalmente em fontes naturais e tem aumentando vertiginosamente, devido à crescente carga de efluentes lançados no ar, na água, nos solos e em toda a biosfera. $\mathrm{O}$ aprimoramento e a intensificação dos sistemas de cultivo animal têm contribuído para melhorar a qualidade e a quantidade de proteína animal, produzida para a alimentação humana. Contudo, o desenvolvimento agrícola ou zootécnico associado a manejos incorretos, tem modificado diversos ecossistemas e impactado, negativamente, diferentes coleções de água como lagos, rios, mares, açudes e até mesmo reservatórios urbanos (FIGUEIREDO et al., 2004).

\section{Cianobactérias e Cianotoxinas}

A deterioração ou a alteração dos parâmetros físico-químicos da água predispõe o crescimento acelerado de plantas superiores e de microalgas, também conhecidas como cianofíceas, algas azuis ou cianobactérias (GOWEN, 1994), muitas das quais são utilizadas como fonte de alimento por várias espécies de peixes (MOHAMED; HUSSEIN, 2006).

As cianobactérias são organismos fotoautotróficos e procariontes, estruturalmente semelhantes às bactérias. Esses organismos fitoplanctônicos dependem basicamente de água, dióxido de carbono, substâncias inorgânicas e luz, obtendo energia, principalmente, por meio da fotossíntese (BEASLEY et al., 1989).

A floração algal, também conhecida como florescimento algal ou "bloom algal" ocorre preferencialmente em água doce, com $\mathrm{pH}$ entre $6 \mathrm{e}$ 9 , contendo elevada concentração de nutrientes (principalmente, nitrogênio e fósforo) e com temperatura entre $15^{\circ}$ e $30^{\circ} \mathrm{C}$. Além de alterar a biodiversidade aquática e as qualidades cênicas locais, a floração de cianobactérias predispõe à morte de organismos aquáticos devido ao decréscimo nos níveis de oxigênio dissolvido e à liberação de substâncias tóxicas denominadas cianotoxinas (BEASLEY et al., 1989; MOHAMED; HUSSEIN, 2006).

A floração das cianobactérias é influenciada por fatores químicos, físicos e biológicos. Em condições ambientais desfavoráveis, como alterações bruscas na temperatura, pode haver a morte de cianobactérias e a liberação das cianotoxinas. Os fatores que levam à formação da toxina não são conhecidos. Contudo, há fortes indícios de correlação entre a formação desta e a sazonalidade, radiação solar, temperatura da superfície da água, $\mathrm{pH}$ e porcentagem de saturação de oxigênio (BEASLEY et al., 1989; CARMICHAEL, 1992; HAIDER et al., 2003). Acredita-se ainda que, a produção e a liberação das cianotoxinas estejam relacionadas com a competição entre os organismos fitoplanctônicos e que possam também atuar inibindo a predação por consumidores primários (larvas de peixes, moluscos, microcrustáceos, dentre outros) (BRASIL, 2003). 
Considerando-se as propriedades toxicológicas, as cianotoxinas podem ser classificadas em neurotóxicas (anatoxina-a, saxitoxina), hepatotóxicas (microcistina, nodularina, cilindrospermopsina) ou irritantes ao contato, devido à presença de lipopolissacarídeos, menos patogênicos que os lipopolissacarídeos de bactérias Gram negativas (MSAGATI; SIAME; SHUSHU, 2006). As cianotoxinas são também consideradas citotóxicas, imunotóxicas, embriotóxicas e genotóxicas (VAJCOVÁ; NAVRÁTIL; PALÍKOVÁ, 1998). Em relação à estrutura química as cianotoxinas podem ser incluídas no grupo dos peptídeos cíclicos (microcistina, nodularina), no grupo dos alcalóides (neurotoxinas, cilindrospermopsina) e no grupo dos lipopolissacarídeos (MSAGATI; SIAME; SHUSHU, 2006).

Várias espécies de cianobactérias podem produzir toxinas potentes em ambientes aquáticos. Dentro de uma mesma espécie podem existir cepas produtoras de toxinas ou não. As toxinas são metabólitos secundários à formação dos fotopigmentos e podem permanecer acumuladas no citoplasma das cianobactérias (CARMICHAEL, 1992; PAER; MILLIE, 1996). No Brasil 82\% das cepas de cianobactérias isoladas são toxigênicas (SOARES; MAGALHÃES; AZEVEDO, 2004). Já foram registradas em diferentes ambientes aquáticos brasileiros pelo menos 20 espécies de cianobactérias potencialmente tóxicas, incluídas em 14 gêneros (SANT'ANNA; AZEVEDO, 2000).

Segundo Vieira et al. (2005) pesquisas têm demonstrado a ocorrência de florações algais, potencialmente tóxicas, em diferentes regiões do país como Rio Grande do Sul, Distrito Federal, Pernambuco, Alagoas, Pará e no Rio de Janeiro. Concentrações de microcistinas entre 0,5 e $100 \mu \mathrm{g} / \mathrm{L}$ foram detectadas em reservatórios de água destinados ao consumo público no Estado de São Paulo e entre 0,5 e 1,11 $\mu \mathrm{g} / \mathrm{L}$, no Estado de Minas Gerais.

No Estado do Paraná pesquisas também demonstraram a ocorrência natural das cianotoxinas em mananciais e na piscicultura regional, atividade que está em ampla expansão (HIROOKA et al.,
1999; KAMOGAE et al, 2006). Neste Estado, Hirooka et al. (1999) detectaram a Microcystis aeruginosa em amostras de água destinadas ao consumo público, à recreação, à aqüicultura e ao consumo de animais. No monitoramento realizado por estes autores, entre 1995 e 1996, foram observadas concentrações de microcistinas entre 0,2 e $6,6 \mu \mathrm{g} / \mathrm{L}$ em águas na região do lago Itaipu, destinadas ao consumo público e entre 6,38 e $10 \mu \mathrm{g} /$ L em águas destinadas à recreação. Ainda, entre 1999 e 2001, Kamogae et al. (2006) relataram concentrações de microcistinas variando entre 0,134 e $240 \mu \mathrm{g} / \mathrm{L}$ e também de florações tóxicas, em rios desse mesmo Estado.

\section{Microcistina}

Existem 150 gêneros com aproximadamente 2000 espécies de cianobactérias, das quais 40 são conhecidamente toxigênicas (HAIDER et al., 2003). As espécies identificadas como produtoras de hepatotoxinas estão incluídas nos gêneros Microcystis, Anabaena, Nodularia, Oscillatoria, Nostoc e Cylindrospermopsis, dos quais se destaca a Microcystis aeruginosa (CARMICHAEL, 1992).

A estrutura química das microcistinas, heptapeptídeos cíclicos, é constituída por três Daminoácidos: $\beta$-eritro- $\beta$-metil ácido aspártico, alanina e $\gamma$-ácido glutâmico (D-ßMeAsp, D-Ala e D-Glu) na porção invariável da molécula, dois L-aminoácidos variáveis e dois aminoácidos raros (Mdha e Adda). O Mdha é o N-metildehidroalanina e o Adda, ao qual se atribui a hepatotoxicidade da microcistina (CHORUS; BARTRAM, 1999) é o 3-amino-9metoxi-10-fenil-2,6,8,trimetildeca-4,6-ácido dienóico. Existem mais de 80 análogos de microcistinas diferenciadas pela constituição dos L-aminoácidos, nas posições “2” (ou "X") e “4” (ou “ $Z$ "). Dentre os análogos mais freqüentes e mais tóxicos, destaca-se a microcistina-LR (Figura 1), constituída dos aminoácidos leucina (L) e arginina (R), seguida da microcistina-RR (arginina; arginina) e microcistinaYR (tirosina; arginina) (FIGUEIREDO et al., 2004; FALCONER; HUMPAGE, 2005). 


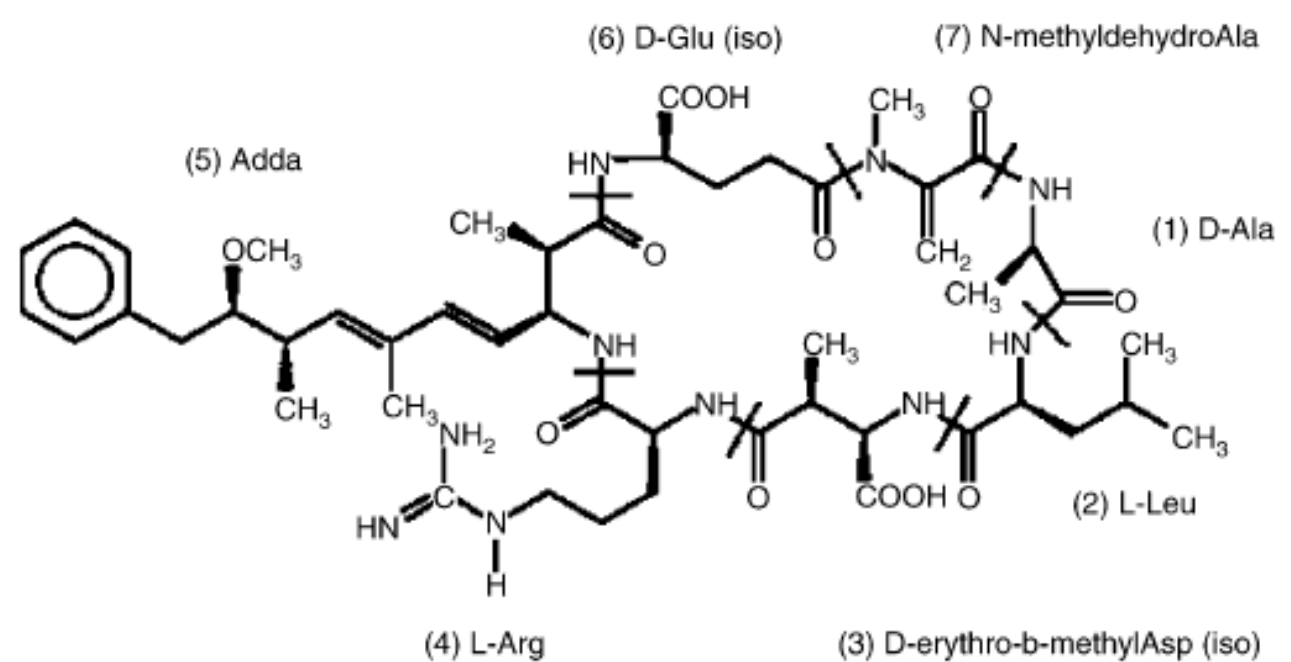

Figura 1. Estrutura química da microcistina-LR. Fonte: CHEN et al., 2006.

Fisiopatologia da intoxicação por microcistina

O fígado é o órgão alvo da microcistina, visto que a citotoxicidade é mais acentuada nos hepatócitos do que em outros tipos celulares (McDERMOTT et al., 1998; ZHAN et al., 2004). Contudo, necrose e/ ou apoptose podem ocorrer não somente nestas células. Estudos in vitro demonstraram os efeitos citotóxicos da microcistina-LR em células humanas como eritrócitos, linfócitos, células endoteliais, epiteliais e fibroblastos (McDERMOTT et al., 1998; LANKOFF et al., 2004; SICINSKA et al., 2006), bem como em promielócitos de ratos (McDERMOTT et al., 1998) e em linfócitos de galinha e de carpas (LANKOFF et al., 2004; ZHANG; ZHANG; CHEN, 2006). Estudos in vivo relataram também efeitos nefrotóxicos em ratos (MILUTINOVIC et al., 2003), em carpas (RABERGH; BYLUND; ERIKSSON, 1991; FISCHER; DIETRICH, 2000) e em trutas (KOTAK et al., 1996) e ainda, efeitos citotóxicos gastrintestinais em camundongos (BOTHA et al., 2004) e em ratos (NOBRE et al., 2004).

Quando há ingestão de cianobactérias, a microcistina é liberada no estômago ou, preferencialmente, no íleo. Uma vez absorvida, a microcistina rapidamente chega ao fígado pela circulação sangüínea (portal) e por meio de receptores dos ácidos biliares, interage com os hepatócitos, provocando alterações no citoesqueleto celular (microfilamentos de actina e filamentos intermediários) (BEASLEY et al., 1989). A perda da adesão intercelular e a retração dos hepatócitos são responsáveis também pela perda de contato destes com os capilares sinusóides. A destruição da arquitetura hepática ocasiona, em minutos ou horas, choque hipovolêmico devido ao seqüestro de sangue pelo fígado (hemorragia intra-hepática) (LeCLAIRE; PARKER; FRANZ, 1995) ou insuficiência hepática, em algumas horas ou dias (BEASLEY et al., 1989). Devido à perda de adesão intercelular, hepatócitos de animais de laboratório inoculados com microcistina-LR já foram observados, eventualmente, no lúmen de vasos sangüíneos pulmonares e renais (BEASLEY et al., 1989; HOOSER et al., 1990).

Weng et al. (2007) salientaram que a microcistina (MC-LR) é responsável pela indução de apoptose de hepatócitos e pela destruição da arquitetura hepática, embora os mecanismos envolvidos não estejam completamente esclarecidos. Segundo estes autores, em camundongos inoculados intraperitonealmente com MC-LR, em dose única (60 $\mu \mathrm{g} / \mathrm{Kg}$ de peso corporal, por 12 horas), a microcistina induziu estresse oxidativo, diminuição do potencial da membrana mitocondrial e expressão das proteínas Bax e Bid, ativando assim os sinais desencadeadores da apoptose, como a ativação das caspases. 
McDermott et al. (1998) relataram que a apoptose pode estar relacionada à hiperfosforilação de proteínas do citoesqueleto (citoqueratina 8 e 18), bem como com a hiperfosforilação de proteínas mais diretamente envolvidas com este tipo de morte celular (p53, Bcl-2). Segundo estes autores, no estudo in vitro, baixas doses de microcistina $(0,8 \mu \mathrm{M})$ induziram a apoptose em hepatócitos de ratos, 30 minutos após a exposição, enquanto que em outros cultivos celulares (fibroblasto humano, células endoteliais humanas, promielócitos de ratos) a apoptose foi observada na exposição à dose de $100 \mu \mathrm{M}$. Fu et al. (2005) relataram que a apoptose induzida pela microcistina-LR está associada à alteração na expressão das proteínas p53, Bcl-2 e Bax, tanto in vivo quanto in vitro.

Fischer et al. (2000) realizaram ensaio experimental com trutas (Oncorhynchus mykiss) e observaram que a necrose pode estar associada à inibição reversível ou irreversível das proteínas fosfatases-1 (PP-1) pela microcistina, enquanto que a apoptose, pode estar associada à inibição irreversível das proteínas fosfatases-2 (PP-2). Esta hipótese justificaria porque, em exposições subcrônicas, ocorrem áreas de necrose de hepatócitos, próximas a áreas com hepatócitos normais ou em apoptose. Zhang, Zhang e Chen (2006) demonstraram in vitro que em linfócitos de carpas a microcistina-LR (MC-LR) e a microcistina-RR (MC$\mathrm{RR}$ ) induzem a apoptose. Os autores sugerem que ensaios que detectem a ocorrência de apoptose poderiam ser utilizados como biomarcadores da floração de cianobactérias toxigênicas.

A PP-1 desempenha importante papel em vários processos celulares (genéticos, bioquímicos). Mutações nesta proteína seriam responsáveis por defeitos na mitose, meiose, na integridade celular e no metabolismo do glicogênio. A PP-2 também está associada com a integridade do citoesqueleto e assim como a PP-1, participa na modulação da motilidade celular, diferenciação e citocinese. Ambas as proteínas regulam a proteína quinase dependente de cálcio/calmodulina (LIN et al., 1999 e SONTAG, 2001 apud AOYAMA et al., 2003; XING et al., 2006).
Além de alterar o citoesqueleto celular, em doses subletais crônicas, a microcistina inibe as proteínas fosfatases (PP-1 e PP-2A), que em conjunto com as quinases protéicas regulam o mecanismo de fosforilação e desfosforilação das proteínas, desempenhando um importante papel no processo de divisão celular. Deste modo, a exposição contínua a doses não letais estimulam a proliferação celular, sendo por isso, consideradas promotoras de carcinogênese (NISHIWAKI-MATSUSHIMA et al., 1992). Vale ressaltar que diversos carcinógenos genotóxicos ou não genotóxicos, direta ou indiretamente, podem iniciar células neoplásicas ou gerar células pré-iniciadas, suscetíveis à ação dos diversos agentes promotores, conhecidos ou não (ELLINGER-ZIEGELBAUER et al., 2005).

Em ensaio experimental agudo (72 horas) com tilápias (O. niloticus), Santos et al. (2007) relataram a marcação imunoistoquímica positiva ao antígeno nuclear de proliferação celular (PCNA) nos hepatócitos dos peixes expostos à microcistina, por imersão e por inoculação intraperitoneal. Segundo os autores, os resultados indicam ter havido estímulo à proliferação de hepatócitos nos animais expostos à microcistina, que é considerada promotora tumoral.

Recentemente, foi também atribuído as microcistinas, ação no estresse oxidativo e na geração de espécies reativas de oxigênio (EROs), bem como nas respostas antioxidantes, mecanismos estes considerados compensadores e/ou protetores (JOS et al., 2005; PRIETO et al., 2006). Estes autores observaram que o estresse oxidativo provocado pelas microcistinas (LR e RR) leva à intensa peroxidação lipídica do fígado, rim e brânquias de tilápias (Oreochromis sp.), sendo também responsável pelo aumento da atividade das enzimas superóxido dismutase e da catalase. Sicinska et al. (2006) também observaram danos na membrana celular de eritrócitos humanos, quando da exposição in vitro, principalmente na dose de $100 \mathrm{nM}$ de microcistinaLR. As alterações celulares observadas por estes autores poderiam decorrer da ligação covalente da microcistina-LR com resíduos (-SH) de proteínas ou estar associadas ao estresse oxidativo. 
Danos teciduais também associados ao estresse oxidativo induzido pela microcistina foram descritos por Pinho et al. (2005) em caranguejos (Chasmagnathus granulatus), uma vez que as cianobactérias fazem parte da dieta destes animais. Estes autores também atribuíram a microcistina a intensa peroxidação lipídica observada na região do hepatopâncreas desta espécie, sugerindo que o aumento na geração de EROs induz também ao aumento do metabolismo aeróbico celular, favorecendo assim, a intensa degradação do glicogênio hepático e o aumento da síntese e da liberação de glicose. Esta hipótese pode estar relacionada à inibição principalmente das proteínas fosfatases-1 (AOYAMA et al., 2003) e provavelmente, associada também à alteração do metabolismo do glicogênio, relatada em tilápias (JOS et al., 2005; PRIETO et al., 2006), em carpas (RABERGH; BYLUND; ERIKSSON, 1991) e em camundongos (GEHRINGER et al., 2003).

Milutinovic et al. (2003) relataram que os mecanismos responsáveis pela hepatotoxicidade aguda causada pela microcistina em ratos (Rattus norvegicus), foram também responsáveis pela nefrotoxicidade crônica observada nestes animais. Para estes autores, exposições crônicas à microcistina em baixas doses são também, potencialmente nefrotóxicas, sendo observado colapso dos capilares glomerulares, corpúsculos renais hipertrofiados com cápsula de Bowman mais delgada e dilatação do espaço de Bowman, além de dilatação de túbulos contorcidos proximais e distais com material eosinofílico no lúmen. Células tubulares com vacuolização citoplasmática, infiltrado inflamatório linfocitário e edema intersticial foram também relatados. A apoptose observada nas células tubulares, segundo os autores, seria decorrente de alterações no citoesqueleto (filamentos de actina).

\section{Exposição às cianotoxinas e sinais clínicos}

As primeiras intoxicações de populações humanas decorrentes do consumo de água contaminada por cepas tóxicas de cianobactérias, foram descritas na Austrália, Inglaterra, China e África do Sul (FALCONER, 1994).

Algumas algas ou os subprodutos destas podem produzir odores e sabores indesejáveis na água. Contudo, a ausência destes sinais não implica na ausência de cianobactérias e de cianotoxinas (CHORUS; BARTRAM, 1999). Por isso, intoxicações agudas envolvendo a ingestão acidental de água contendo metabólitos secundários de cianobactérias são mais freqüentes nos animais do que no homem (BEASLEY et al., 1989). No entanto, a ingestão de microcistina, em baixas concentrações e por longo período, pode predispor ao desenvolvimento de carcinoma hepático, como observado na China, onde a ingestão de água contaminada pela microcistina foi relacionada a uma incidência oito vezes maior de câncer hepático primário (YU, 1989; YU, 1995).

Codd, Metcalf e Beattie (1999) relataram que lavagens caseiras podem não remover eficientemente células de Microcystis aeruginosa das folhas de alface cultivada e irrigada com águas contaminadas, demonstrando outra importante forma de exposição às cianotoxinas.

Em organismos aquáticos a exposição pode ocorrer por via oral pela ingestão de cianobactérias ou pela absorção de toxinas extracelulares, presentes na água (CARBIS et al., 1997; PINHO et al., 2005).

No Brasil acredita-se que a morte de 88 pessoas na Bahia possa estar relacionada com a ingestão de água contaminada por cianotoxinas (TEIXEIRA et al., 1993). Outro grave incidente ocorreu em Pernambuco, em 1996, no qual morreram mais de 50 pessoas após uma sessão de hemodiálise. Análises confirmaram a presença de microcistinas no carvão ativado utilizado no sistema de filtração de água na clínica e também em amostras de sangue e de fígado dos pacientes que foram a óbito (JOCHIMSEN et al., 1998; CARMICHAEL et al., 2001; YUAN; CARMICHEL; HILBRON, 2006).

Sinais clínicos de hepatotoxicose envolvendo cianotoxinas foram descritos em bovinos, ovinos, 
eqüinos, suínos, patos, cães e em outros animais domésticos e silvestres (CARMICHAEL, 1992; MSAGATI; SIAME; SHUSHU, 2006). Estudos experimentais descreveram a intoxicação por microcistinas em camundongos, ratos, coelhos, porcos (CARMICHAEL, 1992) e em peixes (RABERGH; BYLUND; ERIKSSON, 1991; KOTAK et al., 1996; FISCHER et al., 2000; FISCHER; DIETRICH, 2000).

Nas intoxicações por microcistina há relatos da ocorrência de gastroenterites com diarréia, náuseas, vômitos, cólicas abdominais e epigástricas; febre; hepatite com anorexia, astenia e hepatomegalia; distúrbios respiratórios; distúrbios alérgicos e morte, devido à hemorragia hepática e choque hipovolêmico (BEASLEY et al., 1989; NISHIWAKIMATSUSHIMA et al., 1992; FIGUEIREDO et al., 2004). Parte dos sinais gastrintestinais deve-se à ativação dos macrófagos pela microcistina na mucosa intestinal, à liberação de mediadores inflamatórios e, conseqüentemente, à secreção de água e eletrólitos. A inibição das fosfatases também parece ser fator determinante para a manifestação dos sintomas (NOBRE et al., 2004).

Em bovinos as intoxicações por hepatotoxinas resultam em apatia e fraqueza, anorexia, palidez de mucosas e diminuição no refluxo capilar. Alguns animais podem apresentar atonia ruminal, desidratação, diarréia, além de sinais como rinite, conjuntivite, dispnéia ou bronquite aguda, pleurite e edema pulmonar agudo (BEASLEY et al., 1989).

Os efeitos imunossupressores das cianotoxinas têm sido estudados em ratos e em seres humanos (PALÍKOVÁ et al., 1998). Estudos in vitro, em cultura de linfócitos $\mathrm{T}$ e $\mathrm{B}$, demonstraram que a microcistina-LR estimula o aumento da produção de interleucina 6 (IL6) e a diminuição de IL2, diminuindo assim a atividade funcional linfocitária, devido à indução de apoptose e de necrose (LANKOFF et al., 2004).

Ensaios experimentais demonstraram que a dose letal da microcistina intraperitoneal (DL50 ip) para ratos pode variar de 100-120 $\mu \mathrm{g} / \mathrm{Kg}$ (HOOSER et al., 1990), enquanto que para algumas espécies de peixes a DL50 ip pode atingir $550 \mu \mathrm{g} / \mathrm{Kg}$ (RABERGH; BYLUND; ERIKSSON， 1991). Rabergh, Bylund e Eriksson (1991), Kotak et al. (1996) e Bury et al. (1997) relataram que a morte de peixes relacionada à microcistina é decorrente de insuficiência hepática e renal, causada pela intensa necrose nestes órgãos.

\section{Bioacumulação de microcistina}

A microcistina tem sido detectada em alimentos (SOARES; MAGALHÃES; AZEVEDO, 2004), em horticulturas (CODD; METCALF; BEATTIE, 1999) e em fontes de água destinadas à recreação ou ao consumo humano (BRASIL, 2004) em quantidades muito além do limite máximo aceitável pela Organização Mundial de Saúde $(0,04 \mu \mathrm{g} / \mathrm{Kg} / \mathrm{dia}$ ou $1 \mu \mathrm{g} / \mathrm{L})$ (FIGUEIREDO et al., 2004) . No Brasil, o limite máximo aceitável está estabelecido pela Portaria do Ministério da Saúde n. 1469, de 29 de dezembro de 2000, que estipula o padrão de potabilidade e os procedimentos e responsabilidades relativos ao controle e vigilância da qualidade da água para consumo humano (BRASIL, 2003).

Pesquisas têm demonstrado o perigo da bioacumulação de microcistina em invertebrados e vertebrados aquáticos, incluindo os peixes, que participam da cadeia alimentar humana (MAGALHÃES; SOARES; AZEVEDO, 2001; MAGALHÃES et al., 2003; FIGUEIREDO et al., 2004; SOARES; MAGALHÃES; AZEVEDO, 2004; PINHO et al., 2005; XIE et al., 2007). Mohamed, Carmichael e Hussein (2003) relataram o acúmulo de microcistina no intestino, no fígado e no rim de tilápias (O. niloticus). Em ensaio experimental, Soares, Magalhães e Azevedo (2004) também relataram bioacumulação de microcistina-LR no músculo e em maior concentração no fígado de peixes (T. rendalli), uma vez que este é o órgão alvo da toxina.

Li et al. (2004) observaram acúmulo de microcistina-LR no fígado $(261 \mathrm{ng} \pm 108,3 \mathrm{ng} / \mathrm{g}$ de 
peixe) e no músculo $(38,3 \pm 12,3 \mathrm{ng} / \mathrm{g}$ de peixe) de carpas (Cyprinus carpio). Segundo estes autores, a microcistina pode ser parcialmente excretada pelas fezes do animal após a biotransformação, sendo o restante da toxina acumulado no fígado, músculo e outros tecidos.

Kamogae et al. (2007) relataram marcação imunoistoquímica positiva no fígado de tilápias $(O$. niloticus) expostas experimentalmente à microcistina. Segundo estes autores a marcação imunoistoquímica nos animais inoculados intraperitonealmente foi mais freqüentemente observada do que nos imersos em água contendo microcistina, em que houve marcação somente na exposição a maior concentração ( $1 \times 10^{5}$ células $\left./ \mathrm{mL}\right)$. Neste estudo, os resultados observados sugerem ter havido menor contaminação nos animais expostos por imersão.

Malbrouck et al. (2003) inocularam microcistinaLR $(125 \mu \mathrm{g} / \mathrm{kg}$ de peso corporal) intraperitonealmente em "goldfish" (Carassius auratus) jovens. Estes autores também observaram acúmulo hepático da toxina. Contudo, após 21 dias do experimento, os autores relataram ter havido diminuição na concentração da toxina no fígado dos animais estudados.

As conseqüências ambientais e os efeitos agudos e crônicos nos animais e no homem dependem da toxicidade da floração de cianobactérias nos reservatórios de água destinados ao consumo ou nos locais destinados ao lazer (natação, pesca) (FIGUEIREDO et al., 2004).

\section{Detecção e quantificação de cianobactérias e de cianotoxinas}

A análise quantitativa e a caracterização da microcistina ou da Microcystis spp. em amostras de água, pode ser realizada por cromatografia líquida de alta eficiência (CLAE), pela ionização Frit-Fab e ionspray (KONDO et al., 1995; YUAN; CARMICHAEL, 2004; OLIVEIRA, 2006) ou pelo imunoensaio ELISA, empregando-se anticorpo antimicrocistina ou anti-Adda, essencial para a atividade biológica da microcistina (HIROOKA et al., 1999; HARADA et al., 2004; MOUNTFORT; HOLLAND; SPROSEN, 2005; OLIVEIRA, 2006). Msagati, Siame e Shushu (2006) compararam a eficiência, a sensibilidade, bem como as vantagens e limitações das principais técnicas disponíveis para a detecção, caracterização e quantificação das hepatotoxinas. Dentre as técnicas avaliadas estavam o bioensaio com camundongos, a eletroforese por capilaridade, ressonância magnética nuclear, cromatografia gasosa, espectrometria de massa, ELISA e a CLAE.

\section{Remoção de cianobactérias e inativação da microcistina}

São vários os processos de tratamento da água para a remoção de microalgas e de cianobactérias, dentre os quais a coagulação-floculação e a clarificação (sedimentação, flotação e filtração rápida). Contudo, os processos convencionais de remoção das cianobactérias não são efetivos na remoção de cianotoxinas. Por isso, são importantes e menos onerosas as medidas de caráter preventivo (BRASIL, 2003).

As microcistinas são muito estáveis e resistentes a hidrólises em pH neutroalcalino. A degradação natural da microcistina depende da irradiação solar ou da exposição artificial a raios ultra-violeta, em intensidade e duração propícias (ALAM et al., 2001; HAIDER et al., 2003; GAJDEK et al., 2004), o que nem sempre é eficaz. Contudo, estas cianotoxinas são suscetíveis à degradação por algumas bactérias, naturalmente encontradas em rios e reservatórios e também em efluentes de esgotos (CHORUS; BARTRAM, 1999; ISHII; NISHIJIMA; ABE, 2004).

Dentre outras medidas utilizadas na inativação de cianotoxinas destacam-se: adsorção com carvão ativado e a oxidação empregando-se cloro, dióxido de cloro, hipoclorito de cálcio, hipoclorito de sódio, permanganato de potássio, oxigênio e ozônio (ozonização) (BRASIL, 2003). 
Nas intoxicações por microcistina, algumas pesquisas têm proposto terapias com anticorpos monoclonais contra microcistina-LR, o uso de protetores hepáticos e do antibiótico rifampicina (NAGATA et al., 1995; DAWSON, 1998). A suplementação alimentar com vitamina E, de propriedade antioxidante, parece ter um efeito protetor contra a exposição crônica à microcistinaLR (GEHRINGER et al., 2003).

Em camundongos, o manitol e a glicose, potentes agentes osmóticos, podem conferir proteção parcial contra a toxicidade da microcistina, pela inativação ou diluição da toxina (HERMANSKY et al., 1991). Da mesma forma, Rao e Bhattacharya (1996) divulgaram que a administração prévia de glutationa à inoculação intraperitoneal de microcistina, minimiza a intensidade da intoxicação, em decorrência da reação glutationa-MC-LR que reduz a concentração da toxina livre, sem evitar, no entanto os danos ao DNA.

É importante destacar que a vigilância contínua dos mananciais de água é um fator fundamental no biocontrole da floração algal. Quanto à densidade de cianobactérias, de acordo com os procedimentos de vigilância da qualidade da água para consumo humano, o Ministério da Saúde estabelece:

1. Nível de Vigilância - estágio inicial da floração de cianobactérias: presença de uma colônia ou cinco filamentos de cianobactérias $/ \mathrm{mL}$ de água bruta até $1 \times 10^{4}$ células $/ \mathrm{mL}$.

2. Nível de Alerta 1 - estabelecimento inicial da floração de cianobactérias: de $1 \times 10^{4}$ a $2 \times 10^{4}$ células de cianobactérias/ mL.

3. Nível de Alerta 2 - confirmação do estabelecimento da floração de cianobactérias com prejuízos na qualidade da água: de $2 \times 10^{4} \mathrm{a}$ $1 \times 10^{5}$ células de cianobactérias/ $\mathrm{mL}$.

4. Nível de Alerta 3 - presença da floração tóxica de cianobactérias no manancial e perigo iminente à saúde da população: superior a $1 \times 10^{5}$ células de cianobactérias/ mL. (BRASIL, 2003).

\section{Conclusão}

Devido à grave hepatotoxicidade, à capacidade de bioacumulação e promoção tumoral, intrínsecas às microcistinas, bem como aos sinais freqüentemente inespecíficos, pesquisas relacionadas a estas cianotoxinas devem ser incentivadas a fim de se detectar a contaminação de alimentos e da água destinada principalmente ao consumo humano e animal. Os agentes de saúde precisam suspeitar de intoxicações em pacientes que tenham tido contato com água possivelmente contaminada por cianobactérias e pela microcistina, a fim de evitar exposições crônicas e o desenvolvimento de carcinogênese hepática. Setores responsáveis pelo abastecimento de água pública devem estar diariamente atentos às florações algais.

\section{Referências}

ALAM, Z. B.; OTAKI, M.; FURUMAI, H.; OHGAKI, S. Direct and indirect inactivation of Microcystis aeruginosa by UV-radiation. Water Research, England, v.35, n.4, p.1008-14, 2001.

AOYAMA, H.; SILVA, T. M. A.; MIRANDA, M. A.; FERREIRA, C. V. Proteínas tirosinas fosfatases: propriedades e funções biológicas. Química Nova, São Paulo, v.26, n.6, p.896-900, 2003.

BEASLEY, V.R.; COOK, W.O.; DAHLEM, A. M.; HOOSER, S. B.; LOVELL, R. A.; VALENTINE, W. M. Algae intoxication in livestock and waterfowl. The Veterinary Clinics of North América: Food Animal Practice, United States, v.5, p.345-361, 1989.

BOTHA, N.; VAN DE VENTER, M.; DOWNING, T. G.; SHEPHARD, E. G.; GEHRINGER, M. M. The effect of intraperitoneally administered microcystin-LR on the gastrointestinal tract of Balb/c mice. Toxicon, England, v.43, n.3, p.251-254, 2004.

BRASIL. Ministério da Saúde. Agência Nacional de Vigilância Sanitária - ANVISA. Portaria 518. 25 de mar. 2004. Estabelece os procedimentos e responsabilidades relativos ao controle e vigilância da qualidade da água para consumo humano e seu padrão de potabilidade, e dá outras providências. Diário Oficial [da] República Federativa do Brasil, Brasília, 26 mar. 2004. Seção 1.

BRASIL. Ministério da Saúde. Fundação Nacional de Saúde - FUNASA. Portaria n. 1469, de 29 de dezembro de 
2000. Cianobactérias tóxicas na água para consumo humano na saúde pública e processos de remoção em água para consumo humano. 2003. Disponível em: <http:/ /portal.saude.gov.br/portal/arquivos/pdf/ mnl_ciano_bacterias.pdf $>$. Acesso em: 23 jun. 2007.

BURY, N. R.; MCGEER, J. C.; EDDY, F. B.; CODD, G. A. Liver damage in brown trout, Salmo trutta L., and rainbow trout, Oncorhynchus mykiss (Walbaum), following administration of the cyanobacterial hepatotoxin microcystin-LR via the dorsal aorta. Journal of Fish Diseases, England, v.20, n.3, p.209-215, 1997.

CARBIS, C. R.; RAWLIN, G. T.; GRANT, P.; MITCHELL, G. F.; ANDERSON, J. W.; McCAULEY, I. A studty of feral carp Cyprinus carpio L., exposed to Microcystis aeruginosa at lake Mokoan, Australia, and possible implication on fish health. Journal of Fish Disease, England, v.20, n.2, p.81-91, 1997.

CARMICHAEL, W. W. Cyanobacteria secondary metabolites - the cianotoxins. The Journal of Applied Bacteriology, England, v.72, n.6, p.445-459, 1992.

CARMICHAEL, W. W.; AZEVEDO, S. M. F. O.; AN, J. S.; MOLICA, R. J. R.; JOCHIMSEN, E. M.; LAU, S.; RINEHART, K. I.; SHAW, G. R.; EAGLESHAM, G. K. Human fatalities from cyanobacteria: chemical and biological evidence for cyanotoxins. Environmental Health Perspectives, United States, v.109, n.7, p.663-668, 2001.

CHEN, T.; CUI, J.; LIANG, Y.; XIN, X.; YOUNG, D. O.; CHEN, C.; SHEN, P. Identification of liver mitochondrial aldehyde dehydrogenase as a potential target for microcystin-LR. Toxicology, Ireland, v.220, p.71-80, 2006.

CHORUS, I.; BARTRAM, J. Toxic cyanobacteria in water: A guide to their public health consequences, monitoring and management. London: E \& FN Spon on behalf of WHO, 1999.

CODD, G. A.; METCALF, J. S.; BEATTIE, K. A. Retention of Microcystis aeruginosa and microcystin by salad lettuce (Lactuca sativa) after spray irrigation with water containing cyanobacteria. Toxicon, England, v.37, n.8, p.1181-1185, 1999.

DAWSON, R. M. The toxicology of microcystins. Toxicon, England, v.36, n.7, p.953-962, 1998.

ELLINGER-ZIEGELBAUER, H.; STUART, B.; WAHLE, B.; BOMANN, W.; AHR, H. J. Comparison of the expression profiles induced by genotoxic and nongenotoxic carcinogens in rat liver. Mutation Research, Netherlands, v.575, n.1-2, p.61-84, 2005.

FALCONER, I. R. Health implications of Cyanobacterial (blue-green algae) toxins. In: STEFENSEN, D.A; NICHOLSON, B. C. Toxic cyanobacteria current status of research and management: Proceedings for an
International Wokshop. Adelaide: American Water Works Association Research Foundation, 1994. p.39-44.

FALCONER, I. R.; HUMPAGE, A. R. Health risk assessment of Cyanobacterial (Blue-Green Algal) toxins in drinking water. International Journal of Environmental Research and Public Health, Basel, v.2, n.1, p.43-50, 2005.

FIGUEIREDO, D. R.; AZEITEIRO, U. M.; ESTEVES, S. M.; GONÇALVES, F. J.; PEREIRA, M. J. Microcystinproducing blooms-a serious global public health issue. Ecotoxicology and Environmental Safety, New York, v.9, n.2, p.151-163, 2004.

FISCHER, W. J.; DIETRICH, D. R. Pathological and biochemical characterization of microcystin-induced hepatopancreas and kidney damage in carp (Cyprinus carpio). Toxicology and Applied Pharmacology, San Diego, v.164, n.1, p.73-81, 2000.

FISCHER, W. J.; HITZFELD, B. C.; TENCALLA, F.; ERIKSSON, J. E.; MIKHAILOV, A.; DIETRICH, D. R. Microcystin-LR toxicodynamics, induced pathology, and immunohistochemical localization in liver of blue-green alga exposed rainbow trout (Oncorhynchus mykiss). Toxicological Sciences, Orlando, v.54, n.2, p.365-373, 2000.

FU, W.; CHEN, J.; WANG, X.; XU, L. Altered expression of p-53, Bcl-2 and Bax induced by microcystin-LR in vivo and in vitro. Toxicon, Elmsford, v.46, p.171-177, 2005.

GAJDEK, P.; BOBER, B.; MEJ, E.; BIALCZYK, J. Sensitised decomposition of microcystin-LR using UV radiation. Journal of Photochemistry and Photobiology Biology, Switzerland, v.76, n.1-3, p.103-106, 2004.

GEHRINGER,M.M.; GOVENDER, S.; SHAH,M.;DOWNING, T. G. An investigation of the role of vitamin $E$ in the protection of mice against microcystin toxicity. Environmental Toxicology, New York, v.18, n.2, p.142-148, 2003.

GOWEN, R. J. Managing eutrophication associated with aquaculture development. Journal Applied Ichthyology, Germany, v.10, p.245-257, 1994.

HAIDER, S.; NAITHANI, V.; VISWANATHAN, P. N.; KAKKAR, P. Cyanobacterial toxins: a growing environmental concern. Chemosphere, Oxford, v.52, n.1, p.01-21, 2003.

HARADA, K. I.; IMANISHI, S.; KATO, H.; MIZUNO, M.; ITO, E.; TSUJI, K. Isolation of Adda from microcystinLR by microbial degradation. Toxicon, Elmsford, v.44, n.1, p.107-109, 2004.

HERMANSKY, S. J.; STOHS, S. J.; ELDEEN,Z. M.; ROCHE, V. F.; MEREISH, K. A. Evaluation of potential chemoprotectants against microcystin-LR hepatotoxicity in mice. Journal of Applied Toxicology, Chichester, v.11, n.1, p.65-74, 1991. 
HIROOKA, E. Y.; PINOTTI, M. H.; TSUTSUMI, T.; YOSHIDA, F.; UENO, Y. Survey of microcystins in water between 1995 and 1996 in Paraná, Brazil using ELISA. Natural Toxins, New York, v.7, p.103-109, 1999.

HOOSER, S. B.; BEASLEY, V. R.; BASGALL, E. J.; CARMICHAEL, W. W.; HASCHEK, W. M. MicrocystinLR-induced ultrastructural changes in rats. Veterinary Pathology, Washington, v.27, n.1, p.9-15, 1990.

ISHII, H.; NISHIJIMA, M.; ABE, T. Characterization of degradation process of cyanobacterial hepatotoxins by a gram-negative aerobic bacterium. Water Research, New York, v.38, n.11, p.2667-76, 2004.

JOCHIMSEN, E. M.; CAMICHAEL, W. W.A. N, J.; CARDO, D. M.; COOKSON, S. T.; HOLMES, C. E. M.; ANTUNES, M. B. C.; FILHO, D. A. M.; LYRA, T. M.; BARRETO, V. S.; AZEVEDO, S. M. F. O.; JARVIS, W. R. Liver failure and death after exposure to microcystins at a hemodialysis center in Brazil. The New England Journal of Medicine, Waltham, v.338, n.13, p.873-878, 1998.

JOS, A.; PICHARDO, S.; PRIETO, A. I.; REPETTO, G.; VÁZQUEZ, C. M.; MORENO, I.; CAMEÁN, A. M. Toxic cyanobacterial cells containing microcystins induce oxidative stress in exposed tilapia fish (Oreochromis sp.) under laboratory conditions. Aquatic Toxicology, Amsterdam, v.72, p.261-271, 2005.

KAMOGAE, M.; HASHIMOTO, E. H.; PÁDUA, C. G.; SOARES, F. S.; BRACARENSE, A. P. F. R. L.; YABE, M. J. S.; ONO, E. Y. S.; BITTENCOURT-OLIVEIRA, M. C.; SANT'ANA, C. L.; TSUTSUMI, T.; NAGATA, S.; UENO, Y.; HARADA, K. I.; HIROOKA, E. Y. Monitoring microcystin and physicochemical parameters: role of agricultural-aquaculture activity in the water quality. Netherlands: Wageningen Academic Publishers, 2006.

KAMOGAE, M.; HASHIMOTO, E. H.; SANTOS, A. P. M. E.; FRANCABANDIERA, A. I.; PÁDUA, C. G.; BRACARENSE, A. P. F. R. L.; BITTENCOURT-OLIVEIRA, M. C.; COLUS, I. M. S.; ITANO, E. N.; KAMAMURA, O.; TSUTSUMI, T.; NAGATA, S.; KI.; H.; UENO, Y;; HIROOKA, E. Y. Imunoistoquímica: detecção de microcistina em tilápia exposta ao extrato de Microcystis aeruginosa (Cyanobacteria). Semina, Londrina, 2007. In press.

KONDO, F.; IKAI, Y.; OKA, H.; MATSUMOTO, H.; YAMADA, S.; ISHIKAWA, N.; TSUJI, K.; HARADA, K. I.; SHIMADA, T.; OSHIKATA, M.; SUZUKI, M. Reliable and sensitive method for determination of microcystin in complicated matrices by Frist-fast atom bombardeament liquid chromatography/mass spectrometry. Natural Toxins, New York, v.3, p.41-49, 1995.

KOTAK, B. G.; SEMALULU, S.; FRITZ, D. L.; PREPAS, E. E.; HRUDEY, S. E.; COPPOCK, R. W. Hepatic and renal pathology of intraperitoneally administered microcystinLR in rainbow trout (Oncorhynchus mykiss). Toxicon, Elmsford, v.34, n.5, p.517-525, 1996.

LANKOFF, A.; CARMICHAEL, W. W.; GRASMAN, K. A.; YUAN, M. The uptake kinetics and immunotoxic effects of microcystin-LR in human and chicken peripheral blood lymphocytes in vitro. Toxicology, Ireland, v.204, n.1, p.23-40, 2004.

LeCLAIRE, R. D.; PARKER, G. W.; FRANZ, D. R. Hemodynamic and colorimetric changes induced by microcystin-LR in the rat. Journal of Applied Toxicology, Chichester, v.15, n.4, p.303-311, 1995.

LI, X. Y.; CHUNG, I. K.; KIM, J. I.; LEE, J. A. Subchronic oral toxicity of microcystin in common carp (Cyprinus carpio L.) exposed to Microcystis under laboratory conditions. Toxicon, Elmsford, v.44, n.8, p.821-7, 2004.

MAGALHÃES, V. F.; MARINHO, M. M.; DOMINGOS, P.; OLIVEIRA, A. C.; COSTA, S. M.; AZEVEDO, L. O.; AZEVEDO, S. M. F. O. Microcystins (cyanobacteria hepatotoxins) bioaccumulation in fish and crustaceans from Sepetiba Bay (Brasil, RJ). Toxicon, Elmsford, v.42, n.3, p.289-295, 2003.

MAGALHÃES, V. F.; SOARES, R. M.; AZEVEDO, S. M. F. O. Microcystin contamination in fish from the Jacarepaguá Lagoon (Rio de Janeiro, Brazil): ecological implication and human health risk. Toxicon, Elmsford, v.39, n.7, p.10771085, 2001.

MALBROUCK, C.; TRAUSCH, G.; DEVOS, P.; KESTEMONT, P. Hepatic accumulation and effects of microcystin-LR on juvenile goldfish Carassius auratus L. Comparative Biochemistry and Physiology Part. C., New York, v.135, n.1, p.39-48, 2003.

McDERMOTT, C. M.; NHO, C. W.; HOWARD, W.; HOLTON, B. The cyanobacterial toxin, microcystin-LR, can induce apoptosis in a variety of cell types. Toxicon, Elmsford, v.36, n.12, p.1981-1996, 1998.

MILUTINOVIC, A.; ZIVIN, M.; ZORC-PLESKOVIC, R.; SEDMAK, B.; SUPUT, D. Nephrotoxic effects of chronic administration of microcystins -LR and -YR. Toxicon, Elmsford, v.42, n.3, p.281-288, 2003.

MOHAMED, Z. A.; CARMICHAEL, W. W.; HUSSEIN, A. A. Estimation of microcystins in the freshwater fish Oreochromis niloticus in a Egyptian fish farm containing a Microcystis bloom. Environmental Toxicology, New York, v.18, n.2, p.137-141, 2003.

MOHAMED, Z. A.; HUSSEIN, A. A. Depuration of microcystins in tilapia fish exposed to natural populations of toxic cyanobacteria: A laboratory study. Ecotoxicology and Environmental Safety, New York, v.63, p.424-429, 2006. 
MOUNTFORT, D. O.; HOLLAND, P.; SPROSEN, J. Method for detecting classes of microcystins by combination of protein phosphatase inhibition assay and ELISA: comparison with LC-MS. Toxicon, Elmsford, v.45, n.2, p.199-206, 2005.

MSAGATI, T. A. M.; SIAME, B. A.; SHUSHU, D. D. Evaluation of methods for the isolation, detection and quantification of cyanobacterial hepatotoxins. Aquatic Toxicology, Amsterdam, v.78, n.4, p.382-397, 2006.

NAGATA, S.; SOUTOME, H.; TSUTSUMI, T.; HASEGAWA, A.; SEKJIMA, M.; SUGANUMA, M.; HARADA, K. I.; UENO, I. Novel monoclonal antibodies against microcystin and their protective activity for hepatotoxicity. Natural Toxins, New York, v.3, n.2, p.78$86,1995$.

NISHIWAKI-MATSUSHIMA, R.; OHTA, T.; NISHIWAKI, S.; SUGANUMA, M.; KOHYAMA, K.; ISHIKAWA, T.; CARMICHAEL, W. W.; FUJIKI, H. R. Liver tumor promotion by the cianobacterial cyclic peptide toxin microcystin-LR. Journal of Cancer Research and Clincal Oncology, Germany, v.118, p.420-424, 1992.

NOBRE, A. C.; NUNES-MONTEIRO, S. M.; MONTEIRO, M. C.; MARTINS, A. M.; HAVT, A.; BARBOSA, P. S.; LIMA, A. A.; MONTEIRO, H. S. Microcystin-LR promote intestinal secretion of water and electrolytes in rats. Toxicon, Elmsford, v.44, n.5, p.555-559, 2004.

OLIVEIRA, E. J. A. A fluorescent-labeled microcystin-LR terbium cryptate. Journal of the Brazilian Chemical Society, Campinas, v.17, n.2, 2006. Disponível em: $<$ http:/ /www.sciello.com.br>. Acesso em: 15 fev. 2006.

PAER, H. W.; MILLIE, D. F. Physiological ecology of toxic aquatic cianobacteria. Journal of Phycology, English, v.35, p.160-167, 1996.

PALÍKOVÁ, M.; KOVÁRU, F.; NAVRÁTIL, S.; KUBALA, L.; PESÁK, S.; VAJCOVÁ, V. The effects of pure Microcystin LR and biomass of blue-green algae on selected immunological indices of carp (Cyprinus carpio L.) and silver carp (Hypophthalmichthys molitrix Val.). Acta Veterinária Brno, Czech Republic, v.67, n.4, p.265-272, 1998.

PINHO, G. L. L.; ROSA, C. M.; MACIEL, F. E.; BIANCHINI, A.; YUNES, J. S.; PROENÇA, L. A. O.; MONSERRAT, J. M. Antioxidant responses and oxidative stress after microcystin exposure in the hepatopancreas of an estuarine crab species. Ecotoxicology and Environmental Safety, New York, v.61, p.353-360, 2005.

PRIETO, A. I.; JOS, A.; PICHARDO, S.; MORENO, I.; CAMEÁN, A. M. Differential oxidative stress responses to microcystins LR and RR in intraperitoneally exposed tilapia fish (Oreochromis sp.). Aquatic Toxicology, Amsterdam, v.77, n.3, p.314-321, 2006.
RABERGH, C. M. I.; BYLUND, G.; ERIKSSON, J. E. Histopathological effects of microcystin-LR, a cyclic peptide toxin from the cyanobacterium (blue-green alga) Microcystis aeruginosa, on common carp (Cyprinus carpio L.). Aquatic Toxicology, Amsterdam, v.20, p.131145,1991

RAO, P. V. L.; BHATTACHARYA, R. The cyanobacterial toxin microcystin-LR induced DNA damage in mouse liver in vivo. Toxicology, Ireland, v.114, n.1, p.29-36, 1996.

SANT'ANNA, C. L.; AZEVEDO, M. T. P. Contribution to the knowledge of potentially toxic Cyanobacteria from Brazil. Nova Hedwigia, Zeitschrift Für Kryptogamenkunde, Alemanha, v.71, n.3-4, p.359-385, 2000.

SANTOS, A. P. M. E.; HASHIMOTO, E. H.; HASEGAWA, M.; KAMOGAE, M.; BITTENCOURT-OLIVEIRA, M. C.; SABINO, M.; UENO, Y.; HARADA, K. I.; HIROOKA, E. Y; BRACARENSE, A. P. F. R. L. Immuno-histopathology of acute microcystin contamination in Nile Tilapia (Oreochromis niloticus). In: INTERNATIONAL IUPAC SYMPOSIUMON MYCOTOXINS AND PHYCOTOXINS, 12., 2007, Istambul. Anais... Istambul: IUPAC, 2007.

SICINSKA. P.; BUKOWSKA, B.; MICHALOWICZ, J.; DUDA, W. Damage of cell membrane and antioxidative system in human erythocytes incubated with microcystinLR in vitro. Toxicon, Elmsford, v.47, n.4, p.387-397, 2006.

SOARES, R. M.; MAGALHAES, V. F.; AZEVEDO, S. M. Accumulation and depuration of microcystins (cyanobacteria hepatotoxins) in Tilapia rendalli (Cichlidae) under laboratory conditions. Aquatic Toxicology, Amsterdam, v.70, n.1, p.1-10, 2004.

TEIXEIRA, M. G. L. C.; COSTA, M. C. N.; CARVALHO, V. L. P.; PEREIRA, M. S.; HAGE, E. Gastroenteritis epidemic in the area of Itaparica, Bahia, Brazil. Bulletin of PAHO, Washington, v.27, n.3, p.244-253, 1993.

VAJCOVÁ, V.; NAVRÁTIL, S.; PALÍKOVÁ, M. The effect of intraperitoneally applied pure Microcystin-LR on haematological, biochemical and morphological indices of silver carp (Hypophthalmichthys molitrix Val.). Acta Veterinária (Brno), Brno, v.67, n.4, p. 281-287, 1998.

VIEIRA, J. M. S.; AZEVEDO, M. T. P.; AZEVEDO, S. M. F. O.; HONDA, R. Y.; CORRÊA, B. Toxic cyanobacteria and microcystin concentrations in a public water supply reservoir in the Brazilian Amazonia region. Toxicon, Elmsford, v.45, p.901-909, 2005.

WENG, D.; LU, Y.; WEI, T.; LIU, Y.; SHEN, P. The role of ROS in microcystin-LR-induced hepatocyte apoptosis and liver injury in mice. Toxicology, Ireland, v.232, p.15-23, 2007.

XIE, L.; YOKOYAMA, A.; NAKAMURA, K.; PARK, H. Accumulation of microcystins in various organs of the 
freshwater snail Sinotaia histrica and three fishes in a temperate lake, the eutrophic Lake Suwa, Japan. Toxicon, Elmsford, v.49, p.646-652, 2007.

XING, Y.; XU, Y.; CHEN,Y.; JEFFREY,P. D.; LIN, Z.; LI,Z.; STRACK, S.; STOCK, J. B.; SHI, Y. Structure of protein phosphatase $2 \mathrm{~A}$ core enzyme bound to tumor-inducing toxins. Cell, Cambridge, v.127, p.341-353, 2006.

YU, S.Z. Drinking water and primary liver cancer. In: TANG, Z.Y.; WU, M. C.; XIA, S. S. (Ed.). Primary liver cancer. Berlin: China Academic Publishers, Beijing SpringerVerlag, 1989. p.30-37.

Primary prevention of hepatocellular carcinoma.

Journal of Gastroenterology and Hepatology, Austrália, v.10, p.674-682, 1995.

YUAN, M.; CARMICHAEL, W. W. Detection and analysis of the cyanobacterial peptide hepatotoxins microcystin and nodularin using SELDI-TOF mass spectrometry. Toxicon, Elmsford, v.44, n.5, p.561-570, 2004.
YUAN, M.; CARMICHAEL, W. W.; HILBORN, E. D. Microcystin analysis in human sera and liver from human fatalities in Caruaru, Brasil 1996. Toxicon, Elmsford, v.48, n.6, p.627-640, 2006.

ZHAN, L; SAKAMOTO, H.; SAKURABA, M.; WU DE S.; ZHANG, L.S.; SUZUKI, T.; HAYASHI, M.; HONMA, M. Genotoxicity of microcystin-LR in human lymphoblastoid Tk6 cells. Mutation Research, v.557, n.1, p.01-06, 2004.

ZHANG, J.; ZHANG, H.; CHEN, Y. Sensitive apoptosis induced by microcystins in the crucian carp (Carassius auratus) lymphocytes in vitro. Toxicology in Vitro, Oxford, v.20, p.560-566, 2006. 
